\title{
Микроболометрические приемники импульсного терагерцового и субмиллиметрового излучения
}

\author{
М.А. Демьяненко \\ Институт физики полупроводников им. А.В. Ржанова СО РАН, \\ Новосибирск, 630090, пр. Ак. Лаврентьева, 13 \\ тел:+7 (383) 330-9055, факс:+7 (812) 333-2771, эл. почта: demyanenko@isp.nsc.ru
}

DOI 10.34077/RCSP2019-54

Высокая чувствительность неохлаждаемых микроболометрических приемников к терагерцовому (ТГц) излучению обеспечивается двумя способами. Первый состоит в применении антенн, связанных с микроболометром резистивным и/или емкостным способом. Второй состоит в применении тонких металлических поглотителей. Первый преимущественно развивается фирмой LETI (Франция) [1], а второй - фирмой NEC (Япония) [2]. В обоих случаях могут применяться дополнительные оптические резонаторы. В настоящее время в обоих вариантах исполнения достигнута пороговая мощность $\approx 40$ пВт/пиксель на длинах волн 100-200 мкм. Быстродействие приемников составляет около 10-15 мс, так что кадровая частота не превышает 60-100 Гц. Для многих приложений длины волн принимаемого излучения должны достигать порядка 1000 мкм, поскольку в этой области спектра прозрачность многих материалов заметно больше, чем на длинах волн 100-200 мкм. Однако, на длинах волн порядка 1000 мкм пороговая мощность вышеуказанных микроболометров повышается до 1000 пВт/пиксель и более.

В России неохлаждаемые микроболометрические приемники ТГц излучения форматом 160x120 и $320 \times 240$ с пороговой мощностью 15 нВт/пиксель на длине волны 130 мкм были разработаны и продемонстрированы в ИФП СО РАН. Относительно низкая чувствительность была обусловлена тем, что измерения проводились на приемниках, разработанных для инфракрасного диапазона, в которых применялись германиевые окна и отсутствовали тонкий металлический поглотитель и антенны. В случае их применения и замены германиевого окна на просветленное кремниевое, пороговая мощность может быть понижена до $1 \mathrm{HB} /$ пиксель. Дальнейшее улучшение чувствительности требует значительного увеличения оптической толщины резонатора, образованного зазором между поглотителем и подложкой, на которой изготовлен микроболометр, что, однако, требует дополнительных технологических усилий.

Применение антенн, связанных с микроболометром емкостным способом эффективно только на длинах волн менее 200 мкм, на более длинных волнах необходимо применение резистивно-связанных антенн, что понижает чувствительность микроболометра вследствие повышенной теплопроводности. Учитывая это, а также то, что источники ТГц излучения, например, такие как квантово-каскадные лазеры, работают в импульсном режиме, в данной работе предлагается конструкция и применение микроболометров с резистивно-связанными антеннами для регистрации импульсного ТГц и субмиллиметрового излучения. Такие микроболометры позволят регистрировать импульсы излучения энергией вплоть до 1 пДж/пиксель. При этом быстродействие составит $\approx 1$ мс, что позволит обеспечить кадровую частоту близкую к 1000 Гц.

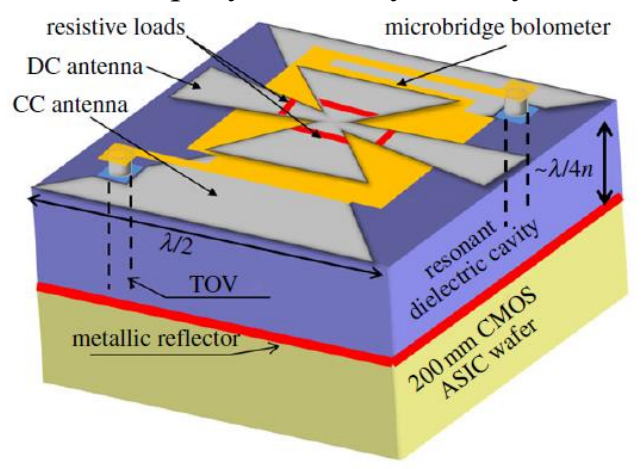

Микроболометр с двумя антеннами, связанными емкостным (CC) и резистивным (DC) способом. LETI (Франция). Пиксель 50 мкм.

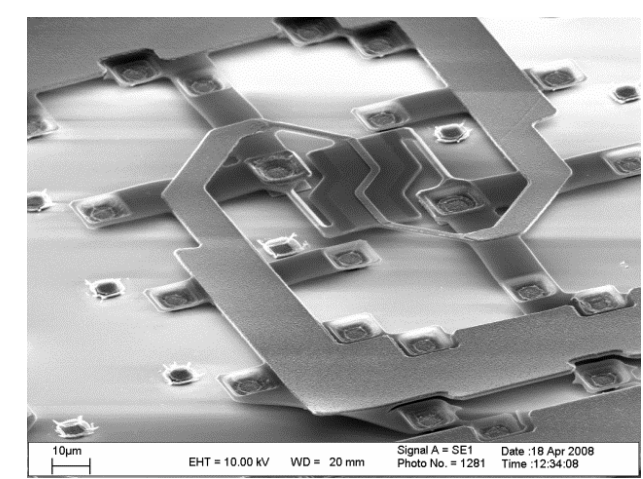

Микроболометр с резистивно-связанной антенной. ИФП СО РАН. Пиксель 250 мкм.

\section{Лumepamypa}

[1] F. Simoens, J. Meilhan // Phil. Trans. R. Soc. A. 2014. Vol. 372, 20130111.

[2] N. Nemoto, etc. // IEEE Trans. on Terahertz Science and Technol. 2016. Vol. 6, P.175-182. 